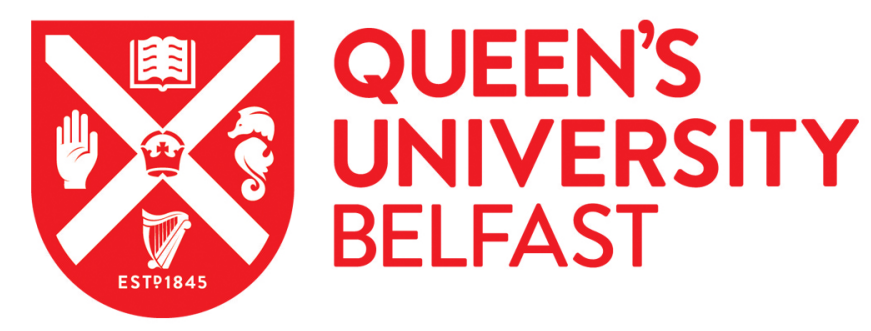

\title{
The emergence of combinations of behavior in an equivalence class without explicit training of a function
}

Keenan, M., Stirrup, L., \& Booth, N. (2021). The emergence of combinations of behavior in an equivalence class without explicit training of a function. Mexican Journal of Behavior Analysis.

\section{Published in:}

Mexican Journal of Behavior Analysis

\section{Document Version:}

Peer reviewed version

Queen's University Belfast - Research Portal:

Link to publication record in Queen's University Belfast Research Portal

\section{Publisher rights}

Copyright 2021 UNAM.

This work is made available online in accordance with the publisher's policies. Please refer to any applicable terms of use of the publisher.

\section{General rights}

Copyright for the publications made accessible via the Queen's University Belfast Research Portal is retained by the author(s) and / or other copyright owners and it is a condition of accessing these publications that users recognise and abide by the legal requirements associated with these rights.

Take down policy

The Research Portal is Queen's institutional repository that provides access to Queen's research output. Every effort has been made to ensure that content in the Research Portal does not infringe any person's rights, or applicable UK laws. If you discover content in the Research Portal that you believe breaches copyright or violates any law, please contact openaccess@qub.ac.uk. 
The emergence of combinations of behavior in an equivalence class

without explicit training of a function

Mickey Keenan \& Lucinda Stirrup ${ }^{1}$

Ulster University, Coleraine

Nichola Booth

Queens University Belfast

${ }^{1}$ The research was conducted in part fulfilment of the degree of BSc (Hons) Psychology at Ulster University under the supervision of Mickey Keenan. Address correspondence to: Mickey Keenan, School of Psychology, Ulster University, N. Ireland BT52 1SA 


\begin{abstract}
Three experiments using undergraduate participants examined the emergence of responding in an equivalence class despite the absence of any functions being explicitly trained to any stimulus within the class. In Experiment 1, a one-to-many conditional discrimination procedure was used to establish two three-member equivalence classes (A1, B1, C1 \& A2, B2, C2) using nonsense syllables. Participants were then presented with printed versions of the stimuli inside plastic boxes alongside a box of Lego pieces and asked to respond as they felt appropriate. Results showed that Lego pieces were placed on top of the printed stimuli by four out of six participants; consistent class responding occurred for one participant. In Experiment 2, the procedure from Experiment 1 was replicated using the same participants, but this time two stimulus members $(\mathrm{B} 1 \& \mathrm{C} 1)$ were replaced by images of Blue and Green Lego pieces respectively. Responding within classes was more consistent across participants and there was some evidence of blended responding at A1. Experiment 3 replicated the procedure used in Experiment 2, this time with experimentally naive participants. Again, although no functions were explicitly trained, Lego pieces were placed on top of printed versions of the stimuli and blended responding reliably occurred for all participants at A1. Results are discussed in the context of procedures used to investigate the emergence of novel behavior.
\end{abstract}

Key words: equivalence responding, transfer of function, rule following, novel behavior, combinations of behavior, humans 
A burgeoning area of research in recent years has been the study of stimulus equivalence (Pilgrim, 2016, 2019). At the heart of this topic is the quest to explore the dynamics involved in establishing networks of relations between previously unrelated stimuli. In a typical experiment, a conditional discrimination is used to establish a relation between a pair of stimuli (e.g., selection of stimulus B in the presence of stimulus A is reinforced) and following this another relation is established between a second pair of stimuli (e.g., selection of stimulus $\mathrm{C}$ in the presence of stimulus $\mathrm{A}$ is reinforced). Following this training, a variety of relations emerge spontaneously between stimuli without additional training. For example, B-A and C-A relations emerge (i.e., symmetrical relations) as well as B-A and C-B relations (i.e., equivalence relations). When these relations between all three stimuli are evident, as well as reflexive relations for each stimulus (i.e., A-A, B-B, \& C-C), an equivalence class is said to have been established. An everyday example of an equivalence class can be seen in the relations between a picture of a cat, the written word 'cat', the sound 'cat', the sound 'michi' or the written word 'michi'. Together, these stimuli are viewed as constituting to a concept whereby any one can substitute for any other. The procedures used to establish equivalence responding have been used to explore a wide range of psychological phenomena including social attitudes (Keenan et al., 2020) and education (Albright et., al, 2016; Walker \& Rehfeldt, 2012).

Various procedures used in the study of equivalence responding also provide opportunities for exploring principles involved in the generation of novel behavior (e.g., Dougher, Twohig, \& Madden, 2014; Dymond \& Rehfeldt, 2000; Ma, Miguel, \& Jennings, 2016; Sidman, 1994; Sidman \& Tailby, 1982). For example, after using a matching-tosample procedure (i.e., a particular kind of conditional discrimination training) to generate a stimulus equivalence class, a discriminative function can be trained to one stimulus within the class and subsequent tests can examine the effects this training has on other members of 
the class. The general finding is that other members also evidence similar control over responding (e.g., Barnes \& Keenan, 1993; Dougher \& Markman, 1994; Dougher, et al., 1994; Gatch \& Osborne, 19889; Perez et al., 2015; Valverde, Luciano, \& Barnes-Holmes, 2009). In other words, without explicit training these stimuli now control a response in a way similar to the stimulus that was used in the initial training.

Other kinds of novel control by stimuli in an equivalence class have come from studies that systematically varied the 'rules' determining how stimuli are related to each other within an equivalence class (e.g., Barnes-Holmes et al., 2004; Dymond, Roche, Forsyth, Whelan, \& Rhodes, 2007; Hayes, Barnes-Holmes, \& Roche, 2001; Whelan \& BarnesHolmes, 2004.). For example, instead of arranging relations between stimuli within a class such as $\mathrm{A}=\mathrm{B}=\mathrm{C}$, the relations between stimuli could be $\mathrm{A}<\mathrm{B}<\mathrm{C}$. Using the first set of relations, the behavior trained in the presence of A would also be controlled by C. However, in the second set of relations $\mathrm{A}$ and $\mathrm{C}$ would control different, but related behaviors (Dougher, Hamilton, Fink, \& Harrington, 2007).

Whilst early studies relied on training a single function within an equivalence class, a different focus on the topic of novel responding comes from a few studies that have explored the effects of adding more than one instance of discriminative control within an equivalence class using topographically distinct behaviors (e.g., Bones et al., 2001; McVeigh \& Keenan, 2009; Keenan, Porter, \& Gallagher, 2015). Training multiple functions provides the opportunity to examine the kinds of interactions that may happen between functions. For example, in a one-to-many procedure where A-B and A-C relations are trained and discriminative functions are added to $\mathrm{B}$ and $\mathrm{C}$ stimuli, the question arises as to whether or not both the trained behaviors would appear at A in some form or other. All of the studies mentioned here which explored multiple functions found some examples of interactions, but the finding was not robust. Bones et al (2001) examined the effect of adding an additional 
function (the act of stamping feet) to an already established functional equivalence class that controlled clapping of hands. On a few occasions, both clapping and stamping appeared. On other occasions neither of these behaviors occurred, though this result was still technically a behavior whose origins are related to the original trained functions. McVeigh and Keenan (2009) used a drawing response to examine multiple functions in five-member equivalence classes. They trained separate drawings at A1, C1, and E1 in a five-member class comprising A1, B1, C1, D1, and E1. Although only with one participant (Subject 20), they nevertheless observed that behaviors trained at $\mathrm{A} 1$ and $\mathrm{C} 1$ could sometimes appear together at B1, while drawings that appeared at D1 were those that were trained at C1 and E1. For one other participant (Subject 4), all three trained behaviors combined on the last two trials at B1. Using modelling clay, Keenan, Porter, and Gallagher (2015) examined the effects of joining together two separate functional equivalence classes. One class controlled the creation of an oblong shape while the other class controlled the creation of a ball. In a subsequent test they found that three participants produced entirely new shapes at the stimulus used to join the classes. In another study, this time using behaviors with similar topographies (i.e., drawing dots), Schenk, Keenan, and Morren (2015) found further evidence for interactions between functions. They established two three-member equivalence classes (A1, B1, C1 \& A2, B2, C2) and trained behaviors that involved a 'number' and 'color' component; at A1 draw 10 black dots, at $\mathrm{C} 1$ draw 1 black dot, A2 draw 10 red dots, at C2 draw 1 red dot. In tests for transfer of function, they found that across participants, the colours drawn were class consistent (i.e., black dots for A1, B1, C1 and red dots for A2, B2, C2) and the numbers of dots drawn at $\mathrm{A}$ and $\mathrm{C}$ stimuli were generally consistent with the numbers trained. However, at B1 and B2 a variety of dots were drawn across participants. On each occasion, though, participants matched what they had drawn at each of these stimuli such that one participant 
drew 1 dot at each, two drew 2 dots at each, one drew 3 dots at each, one drew 5 dots at each, one drew 9 dots at each, and one drew 11 dots at each.

Because of the limited number of procedural variations used to date to examine multiple functions within equivalence classes, it is not yet possible to come to a general conclusion about the principles that determine outcomes. That is to say, there has been no systematic research to examine the effects of establishing different kinds of discriminative control at different stimuli within an equivalence class using several motor responses that are physically incompatible, or using several motor responses that are physically compatible, or using a mixture of motor responses that are either physically compatible or incompatible with each other, all in classes of varying sizes. The general laws determining the outcomes arising from the design of experimental contingencies to explore these issues will no doubt prove to be difficult to ascertain given the variety of ways to establish equivalence classes, the variety of discriminative functions that could be established, the variety of motor responses that match these criteria, and the variety of rules that could be used for determining the relations between stimuli in a class. Nevertheless, the limited research to date that has explored the effects of multiple functions/behaviors suggests this might be a fruitful strategy for enhancing our understanding of the emergence of novel behavior. The current studies were designed with this general aim in mind. The original goal was to use a one-to-many conditional discrimination procedure (i.e., train A-B and A-C relations) to established two equivalence classes, and then to train a behavior at ' $\mathrm{B}$ ' and a different behavior at ' $\mathrm{C}$ ' to see what behavior emerges in the presence of ' $\mathrm{A}$ ' in a subsequent test. In preparation for this goal, it was originally decided to use the simple behavior of selecting different coloured Lego pieces, one colour in the presence of ' $\mathrm{B}$ ' and a different colour in the presence of ' $\mathrm{C}$ '. However, the goals of the research changed when a variety of behaviors emerged within classes without any specific prior training of discriminative functions in Experiment 1. 


\section{Experiment 1}

\section{Method}

\section{Participants}

Nine undergraduate students (4 males and 5 females) were recruited through the School of Psychology, Ulster University, participant recruitment system; ages ranged from 18-50. All were native English speakers with no previous experience in equivalence research and participation was entirely voluntary, with no incentives or payments offered. Each participant completed a single session that lasted between 30- 60 min in length. Participants were informed that they were free to withdraw from the study at any point in time, for any reason. Participants were fully debriefed on the purpose of the research at the end of the final experiment.

\section{Apparatus and Stimuli}

Each experimental session was conducted in a room located in the School of Psychology. In all experiments, equivalence classes were established on a desktop computer. The on-screen stimuli consisted only of arbitrary words. These words were labelled alphanumerically in relation to placement and position within each stimulus class. These labels were only available to the experimenter and were not seen by the participants. On the screen, the stimuli were $2.7 \mathrm{~cm}$ horizontal x $1.0 \mathrm{~cm}$ vertical in size and were as follows: A1 (ZID), B1 (KAP), C1 (TIV), A2 (YIM), B2 (DOJ), C2 (VEK). Located next to the computer workstation, on the same table, was a box of assorted Lego pieces, containing individual blue, green, red and yellow Lego bricks, with 12 of each colour available. Also located on the table were 6 individual clear plastic containers. Within each container, placed face down, was a printed image of one of the stimuli used to establish the equivalence classes. A camera was used to document the results of Phase 4. 


\section{Procedure}

Overview. A one-to-many conditional discrimination procedure was used to train and test two three-member equivalence classes. There were five phases. Phase 1 (train A-B relations), Phase 2 (train A-C relations), and Phase 3 (test B-C and C-B relations) occurred on the computer. Phase 4 (testing for emergent functions) occurred off the computer, and Phase 5 (re-testing) was a repeat of Phase 3 on the computer. Before the experiment began, participants were provided with a consent form and information sheet and asked to carefully read both and sign and date the consent form once completed. Once each participant arrived, they were asked to take a seat in front of the computer workstation and given the following instructions:

Thank you for taking part in this experiment. In a moment, on the screen in front of you, you will see three arbitrary words appear. One of these words will appear centred at the top of the screen and the other two will appear at the bottom left and right-hand corners. Your task is to look at the word at the top of the screen and select one of the two words at the bottom. You do this by simply moving your mouse cursor over your selected word and clicking once. During the first part, you will be told if your selected word is correct or incorrect immediately after you make your choice. Once this is complete, a screen will appear telling you that you have moved onto the next phase of the experiment and the feedback will no longer appear on screen. Click once on 'Start' once you are ready to begin the experiment. Do you have any questions?

Phase 1: A-B training (on the computer). In Phase 1, the A-B conditional discriminations were trained in blocks of 10 trials. Once the participant clicked 'Start' on the screen, 10 trials began with a sample stimulus (A1) located on the top centre of the screen and comparison stimuli (B1 \& B2) located on the bottom left and right-hand corners respectively. Across trials, the positions of both comparison stimuli 'B1' and 'B2' were counterbalanced, 
appearing in a semi-random order to eliminate any position bias. Directly after every correct response (i.e., selecting 'B1'), the word "Correct" appeared in green text in the centre of the computer screen. After every incorrect response (i.e., selecting 'B2'), the word "Incorrect" appeared in red in the centre of the computer screen. Once the participant had achieved a minimum of $90 \%$ correct responding, the next block of 10 trials began. During this block, 'A2' was used as the sample, and again both 'B1' and 'B2' were the comparison stimuli. Trials proceeded as before. Once a minimum of $90 \%$ correct responding was attained, the program progressed to Phase 2 . If $90 \%$ mastery was not achieved during any block of 10 trials, the block was repeated until the minimum correct mastery criterion was achieved. If mastery was not achieved after 5 repetitions (50 trials), the session was terminated.

Phase 2: A-C training (on the computer). In Phase 2, the A-C conditional discriminations were trained in blocks of 10 trials. The selection of comparison stimulus ' $\mathrm{C} 1$ ' was required in the presence of sample stimulus 'A1' and the selection of comparison stimulus 'C2' was required in the presence of sample stimulus 'A2'. The trials occurred in the same way as A-B training in Phase 1. A minimum of $90 \%$ correct responding rate was required before the participant moved onto Phase 3. If mastery was not achieved after 5 cycles (100 trials), the session was terminated at this point.

\section{Phase 3: testing for emergent relations between B-C and C-B (on the computer). In}

Phase 3, equivalence relations (i.e., B1-C1, B2-C2, C1-B1, C2-B2; 10 trials for each relation in this sequence) were tested. In a semi-random order, participants were presented with either $\mathrm{B} 1 / \mathrm{B} 2$ or $\mathrm{C} 1 / \mathrm{C} 2$ as the sample and comparison stimuli. The selection of comparison stimulus B1 was required in the presence of sample stimulus $\mathrm{C} 1$ and the selection of comparison stimulus B2 was required in the presence of sample stimulus C2. The selection of comparison stimulus $\mathrm{C} 1$ was required in the presence of sample stimulus B1 and the selection of comparison stimulus $\mathrm{C} 2$ was required in the presence of sample stimulus B2. The positions of 
both comparison stimuli were counterbalanced in order to eliminate any position bias.

Participants were informed that they were moving on to the next phase of the experiment and would no longer receive feedback as to whether their responses were correct or incorrect. The positions of both comparison stimuli were counterbalanced in order to eliminate any position bias. If participants achieved $90 \%$ correct responding, they proceeded to Phase 4 . If the score was lower than $90 \%$, the participant remained in Phase 3 until this criterion was achieved. If the participants were unsuccessful after five cycles (i.e., 5 x 40 trials), the experiment was terminated. At the end of this phase, regardless of whether participants had met mastery criterion, the following message appeared on the screen:

This is the end of this part of the experiment, please contact the experimenter. Thank you for your participation.

Participants who did not achieve the mastery criterion were debriefed about the nature of the study and thanked for their participation. They were also informed that it is not unusual for participants to terminate an experiment at this point.

Phase 4: Testing for emergent functions (off the computer). During Phase 4, participants were relocated to a table located next to the computer workstation. On the table were six clear plastic trays, each one containing a printed version of one of the six stimuli used during the previous training and testing phases. The trays were laid out in a random order in two rows of three, with the stimulus inside placed so that the image was facing down. Cards were placed face down to ensure that a discrete trial occurred without interference from seeing the subsequent cards to be presented. Also placed on the table was a box containing 48 individual Lego pieces; 12 blue, 12 green, 12 red, and 12 yellow. The participants were handed the following written instructions:

I am going to set out six individual flashcards within six clear trays and I am going to leave the room. I would like you to pick up a flashcard from the first tray, look at it, 
place it back in the tray face down, and then respond as you feel appropriate. Once you have done this, pick up the next flashcard in the next tray, look at it, place it back in the tray face down, and respond as you feel appropriate again. When you have finished all the cards, call me and I will take a photograph of what you have done. After taking the photograph, and after I rearranged the order of the trays, you can start the process again. We will repeat this process a total of five times. Do you have any questions because once we proceed, I cannot answer any questions?

When the participant was reading these instructions, the experimenter organised and laid out the trays containing the stimuli from the two three-member classes. Once the participant had read the instructions and any questions had been answered, the experimenter left the room to allow him/her to work unobserved. The participant signalled to the experimenter when they had finished. At this point, the results were photographed, and the arrangement of the trays was changed for the next trial. This sequence occurred a total of five times before the participant moved onto Phase 5.

Phase 5: Re-testing of Phase 3 (on the computer). During this phase, the participants were moved back to the computer workstation. They were required to repeat Phase 3 , the testing for emergent relations between B-C and C-B.

\section{Results}

Percentage equivalence scores for each participant in Phases 3 and 5 respectively were as follows: P2 (99\% \& 97\%); P4 (99\% \& 95\%); P6 (96\% \& 100\%); P7 (100\% \& 100\%); P8 (100\% \& 100\%); P9 (96\% \& 97\%); participants P1, P3, and P5 did not meet the criteria to move onto Phase 4 and were thus eliminated from the study. Photographs were taken of the contents of the plastic boxes on each trial, with each stimulus card face up. The experimenter and a second independent observer examined the photographs and separately recorded the contents of each box (i.e., the color and frequencies of any lego, whether or not they were 
simply placed beside each other or whether they were physically joined together) for each stimulus. Interobserver agreement was calculated by taking the number of agreements between the observers and dividing by the total number of agreements plus disagreements and then multiplying 100; the percentage (\%) of agreement was $100 \%$ on all occasions. The results obtained are presented in the left-hand panel of Figure 1. Three participants were unable to progress to Phase 4 (1 male and two females) and their participation was terminated. Equivalence scores for remaining participants were consistently above $95 \%$ across all remaining participants in Phases 3 and 5 for each experiment; all remaining participants in both experiments reached mastery criterion on their first exposure to each phase. Although all remaining participants were not instructed to use Lego pieces at any time in Phase 4, they were used nevertheless and responding differed substantially across participants in terms of which Lego pieces were used, the numbers of Lego pieces used, and whether the pieces were joined or not. Despite this general variability, three general patterns of responding were apparent. Accordingly, in Figure 1 data are not organised sequentially with respect to participant ID but with respect to the different patterns that were observed. Firstly, two participants (P4 \& P6) made no responses in the presence of any of the stimuli during testing for emergent relations. Secondly, all the other participants placed Lego pieces on top of stimuli in both classes on nearly all trials. Of these, two participants (P8 \& P9) placed either one Lego (P8) or mostly pairs of Lego pieces on each of the stimuli. P8 place one yellow Lego on each of the stimuli in Class 1 (A1, B1, C1) and one red Lego on each of the stimuli in Class 2 (A2, B2, C2). Responding was not consistent across trials for P9. The third general pattern of responding occurred for P2 and P7. Both participants placed larger numbers of Lego pieces on each of the stimuli across trials; numbers used for P2 ranged between 1-8, whereas 3 Lego pieces were placed on each of the stimuli by P7. Interestingly, 
P7 was the only participant who consistently joined Lego pieces together; P8 joined pairs of Lego pieces in the presence of 'A1' across all trials.

\section{Discussion}

In this experiment, nonsense syllables were used as stimuli in a matching-to-sample procedure to establish two 3-member equivalence classes (A1B1C1 \& A2B2C2). No additional functions were trained to any of the stimuli in either class. The procedure was intended to function as a baseline assessment of responding in the presence of a box containing different colored Lego pieces before an explicit function was trained to one of the stimuli in a subsequent condition. Only two participants responded as anticipated. That is, in the absence of an explicitly trained function at one of the stimuli, findings from previous research in this area suggest that there should be no responding at any of the stimuli. This was the case for P4 and P6. It was a different story for the other participants. Participant P8 responded differentially between the two classes such that on each trial a Yellow Lego was selected in the presence of A1, and B1, and C1 while a Red Lego was selected in the presence of $\mathrm{A} 2$, and $\mathrm{B} 2$, and $\mathrm{C} 2$. This pattern looks remarkably like evidence for the emergence of two functional equivalence classes, but notably without the occurrence of explicit training of a response to any member of either equivalence class. Differential responding between classes and across trials occurred also for P7 who picked groups of three Lego pieces in the presence of each stimulus. Responding for the other participants was irregular, but again, Lego pieces were selected in the presence of each stimulus on each trial. Collectively, these results are surprising insofar as they indicate that it is possible for stimuli in an equivalence class to control responding in the absence of explicit training of a discrete function, as long as particular environmental cues are present. Once selected, though, there was variability in how Lego pieces were distributed with respect to the structure of the equivalence classes. Usually, variability in responding is attributed to weak control by 
putative independent variables. An alternative view, however, comes from Keenan et al., (2020) and Watt et al (1991) who demonstrated that history effects can have a bearing on the extent of variability observed in responding in equivalence classes.

In the design of the current testing context, there were potentially four variables that collectively influenced the behaviours observed after MTS training. These were the presence of the box containing Lego pieces, the trays containing the stimulus cards, the stimulus cards, and the instruction to 'respond as you consider appropriate'. Given that this combination of variables unexpectedly produced what looked like responding in functional equivalence classes, it was decided to change the focus of the study and explore the impact of changing one feature of the testing context. In the next experiment, stimuli in one of the classes were changed from nonsense syllables to pictures of Lego pieces. Perhaps this design change would affect the variability in responding since the inclusion of pictures of Lego pieces might act as a more salient prompt to select Lego pieces. Again, there was no attempt to directly train a specific response to any stimulus. B1 and C1 stimuli were changed from nonsense stimuli to pictures of blue and green Lego pieces respectively. If the new B1 and C1 stimuli each controlled selection of specific Lego pieces, it would be interesting to see what happens at A1. Would there be some sort of combined effect such that control by B1 and C1 stimuli is duplicated at A1? This strategic design in the method is also aligned with the original goal of these studies insofar as the outcomes might contribute to our understanding of multiple functions in equivalence classes.

\section{Experiment 2}

\section{Method}

\section{Participants}

Participants P2, P4, P6, P7, P8, P9 used in Experiment 1 were used here. 


\section{Procedure}

This was a re-run of the general training and testing procedures in Experiment 1, conducted on a different day that suited each participant. This time, however, while all the other stimuli remained unchanged, the stimuli used for two members of one of the equivalence classes (i.e., B1 (KAP) \& C1 (TIV)) were changed from nonsense syllables to photographic images of individual coloured Lego bricks (B1 (Blue Lego) \& C1 (Green Lego)); image sizes were not changed from those used in Experiment 1.

\section{Results \& Discussion}

Percentage equivalence scores for each participant in Phases 3 and 5 respectively were as follows: P2 (100\% \& 99\%); P4 (99\% \& 100\%); P6 (100 \% \& 100\%); P7 (100\% \& 100\%); P8 (100\% \& 100\%); P9 (100\% \& 100\%). Results obtained are presented in the right-hand panel of Figure 1 to facilitate comparison with those obtained in Experiment 1; interobserver reliability was calculated as in Experiment 1 and was $100 \%$ when photos of data were assessed across trials. Equivalence scores for remaining participants were consistently above 95\% across all participants in Phases 3 and 5; all participants reached mastery criterion on their first exposure to each phase. Participants again used Lego pieces although not instructed to do so. There were marked changes in responding for all participants compared to Experiment 1. P4 and P6, who previously did not use Lego pieces, now used them in Class 1 (A1, B1, C1), but not for Class 2 (A2, B2, C2). Single Lego pieces were used by both participants for 'B1' and ' $\mathrm{C} 1$ ', and the responses were generally consistent across trials; $\mathrm{P} 6$ used pieces that matched the colours of ' $\mathrm{B} 1$ ' and ' $\mathrm{C} 1$ ', while the colours were reversed for P4. At 'A1', Blue Lego dominated across trials, but pairs of Green and Blue Lego were used by P6 on every trial. For P8 and P9, responding was similar to that observed for P6 and P4 respectively in Class 1; Lego pieces were physically joined together at 'A1' on every trial for P8. P8 and P9 also used Lego pieces in Class 2. P8 used Red Lego pieces for all stimuli 
across trials, while pairs of Lego were used by P9; responding was only consistent for P9 at 'A2'. For P2, responding was again inconsistent across stimuli and across trials. For P7, there was a reduction in the overall degree of variability in responding compared to Experiment 1. Class 2 was now comprised mostly of Red and Yellow Lego pieces joined together in varying numbers. In Class 1, Blue-Green combinations of Lego pieces predominated at 'A1', with Blue-Yellow combinations dominating at 'B1', and Green-Yellow combinations dominating at ' $\mathrm{C} 1$ '.

Insert Figure 1 about here

The inclusion of Lego pieces in Class 1 resulted in more consistent class responding across three participants compared to Experiment 1. Now, P6, P8, and P9 each selected one Lego piece across trials for each of 'B1' and ' $\mathrm{C} 1$ ' and two Lego pieces across trials for 'A1'. The colors selected by P6 and P8 at 'B1' and ' $\mathrm{C} 1$ ' matched those depicted in the image for each stimulus; for P9 the colours were reversed. For P2, the general variability in responding was relatively unaffected except for a reduction in the numbers of clusters of Lego pieces; the numbers of clusters with 3 and above were 15 in Experiment 1, but only 4 in Experiment 2. Previously for P7, clusters of 3 Lego pieces were used for all stimuli in both classes. This time, only on the first trial were clusters of 3 used with the rest of the trials containing mostly 2 Lego pieces. For three participants (P6, P8, P9), the single-colored Lego pieces used at 'B1' and ' $\mathrm{C} 1$ ' appeared together at 'A1', and one participant (P8) physically joined them. The next experiment examined the procedure used in Experiment 2 with experimentally naïve participants. This would help establish whether the appearance of consistent combinations of Lego pieces at 'A1' was a direct result of the procedure used and not an artefact produced because of prior responding in Experiment 1. 


\section{Experiment 3}

\section{Method}

\section{Participants}

Five undergraduate students ( 2 males and 3 females) were recruited through the School of Psychology, Ulster University, participant recruitment system; ages ranged from 18-50. All were native English speakers with no previous experience in equivalence research and participation was entirely voluntary, with no incentives or payments offered. Each participant completed a single session that lasted between 30- 60 min in length. Participants were informed that they were free to withdraw from the study at any point in time, for any reason. Participants were fully debriefed on the purpose of the research at the end of the final experiment.

\section{Procedure}

Al participants were trained and tested using the procedure described in Experiment 2.

\section{Results}

One male participant was unable to progress to Phase 4 and their participation was terminated. Percentage equivalence scores for each remaining participant in Phases 3 and 5 respectively were as follows: P10 (100\% \& 100\%); P11 (91\% \& 100\%); P12 (100\% \& $100 \%) ; \mathrm{P} 14(100 \% \& 100 \%)$. Figure 2 shows the results for all remaining participants in Experiment 3; interobserver reliability was calculated as described previously and was $100 \%$ when photos of data were assessed across trials. Equivalence scores were consistently above 90\% across all remaining participants in Phases 3 and 5. For all remaining participants, Lego pieces were selected and placed on top of stimuli in Class 1 on all trials. In Class 1, there was some consistency in the selection of Lego pieces across trials for each stimulus for all remaining participants. At 'A1', both P11 and P12 selected pairs of Blue and Green Lego combinations across all trials. P10 also selected this colour combination, however, the 
number of pieces placed varied considerably across trials. Responding for P14 at A1 was the least consistent and the greatest numbers of Lego pieces were used by this participant; however, Blue and Green colours dominated. At 'B1' and 'C1', responding was most consistent across all trials for P11 and P12; each placed Green Lego pieces at 'B1' and Blue Lego pieces at ' $\mathrm{C} 1$ '. For P10 and P14, responding was less consistent, but again only single coloured pieces were ever used. In Class 2, two general patterns of responding occurred. Three participants (P10, P12, \& P14) made no responses in the presence of any of the stimuli, whereas P11 mostly used single coloured Lego (Yellow or Red) at 'A2' and 'B2' respectively, and combinations of Yellow and Green at 'C2'.

Insert Figure 2 about here

\section{General Discussion}

In planning for the current studies, the original aim was to use pictures of blue and green Lego pieces as ' $\mathrm{B} 1$ ' and ' $\mathrm{C} 1$ ' stimuli respectively and train a function at each stimulus (e.g., build pairs of blue Lego pieces at 'B1' and build pairs of green Lego pieces at 'C1') before using a one-to-many conditional discrimination procedure for establishing two threemember equivalence classes (A1, B1, C1 \& A2, B2, C2). This procedure would show whether or not both of the trained functions combined in some way at 'A1'. The rationale for doing this was based on the findings from a few studies that have examined the effects or training more than one function in an equivalence class (Barnes, Browne, Smeets, \& Roche, 1995; Bones et al., 2001; Fields et al. 1995; Fields \& Watanabe-Rose, 2008; McVeigh \& Keenan, 2009; Keenan, Porter, \& Gallagher, 2015). Some of these studies demonstrated that training multiple functions can lead to the appearance of combined functions. The procedures 
described in the experiments reported here were initially designed to provide baseline assessments before multiple functions were trained in the way described. Experiment 1 examined responding when only nonsense syllables were used as stimuli. Unexpectedly, it was found that it was not necessary to explicitly train any functions for stimuli to evidence control over responding. After equivalence responding was established, participants were prompted to respond in any way they choose during a test where class members were contained within separate plastic boxes that sat alongside a larger plastic box containing different coloured Lego pieces. All participants tested, apart from P4 and P6, placed Lego pieces into the plastic boxes. Surprisingly, one participant (P8) placed the Lego in a manner that was class consistent, placing a single yellow piece in each box containing a Class 1 stimulus and a single red piece in each box containing a Class 2 stimulus across all test trials. For the other participants tested, a different kind of consistency was observed in that Lego pieces were placed on each stimulus across nearly all trials; responding, though, was much more variable, while on some occasions the same combination of Lego pieces was used across trials by participants. Responding at 'B1' and ' $\mathrm{C} 1$ ', as well as at 'B2' and 'C2', was inconsistent across trials and across participants, and there was no evidence of combined functions at either 'A1' or 'A2' respectively.

In Experiment 2, when pictures of Lego were used as ' $\mathrm{B} 1$ ' and ' $\mathrm{C} 1$ ' stimuli, there was clear evidence of combined functions at 'A1' for three participants (P6, P8, \& P9). Alongside this effect, there was consistent differential responding across trials for all three participants at ' $\mathrm{B} 1$ ' and ' $\mathrm{C} 1$ '. These general findings were replicated in Experiment 3 when the procedures were used with naïve participants. Interestingly, the behaviors at 'B1' and C1 are technically emergent behaviors. This means that behaviors at 'A1' were combinations of emergent behaviors, not simply emergent combinations derived from explicitly trained functions. The similarity in results between Experiment 2 and Experiment 3 indicates that 
prior history with Experiment 1 was not needed to facilitate this effect. Furthermore, results from Experiment 3 also suggest that the variability in responding across trials and stimuli for all participants tested in Experiment 2 was directly related to the initial findings from Experiment 1.

The finding that responding occurred within classes in the absence of direct training could be viewed casually as a demonstration of 'demand effects' in an equivalence study. Comments from some students afterwards indicated that they felt they had to do something with the Lego pieces on the table. Implicit demands are difficult to control in any experimental investigation (Nichols \& Maner, 2008), yet they need to be recognised as a contributing factor to many research findings. That said, the term 'demand effect' is best replaced by reference to the roles of current and historical contexts. All participants entered the testing environment after a recent history of relational responding in accordance with the scheduled contingencies of the one-to-many match-to-sample procedure. Also, all participants had an extensive personal history of picking up items in one location and placing them in another location. The presence of empty boxes beside a box full of items, and the instruction to 'respond', probably resulted in generalised rule following (Hayes \& Hayes, 1989) so that items were transferred to the empty boxes; a repeat of the procedure without any stimulus cards in the boxes would help verify this possibility. McGuigan and Keenan (2002) showed that instructions could be used to generate a transfer/transformation of function effect with a simple motor response. Their instructions were stimulus and response specific compared to instructions used here. Nevertheless, the instruction to respond in this context initiated the behavior of transferring Lego pieces for most participants, and the subsequent distribution of the Lego pieces was influenced by the recent history of equivalence responding. The significance of this general finding is perhaps best illustrated by 
the findings for P8 in Experiment 1. The data appeared remarkably similar to those that would be found in a traditional transfer/transformation of function study.

Currently, the reporting of functional equivalence classes in the experimental literature is closely tied to particular features of procedures used to establish them. A specific function is directly trained to a member of an equivalence class (either before or after equivalence responding is established) and when all class members subsequently share the same function, the equivalence class is redefined as a functional equivalence class (Barnes \& Keenan, 1993; Dougher \& Markman, 1994; Sidman, 1994). Finding reported here suggest that general history effects also can be considered as contributing to the eventual emergence of functional equivalence responding in studies of functional equivalence. This argument applies equally to the performances of all participants who used Lego pieces, irrespective of the distribution of responses within classes. Although the stimuli in the classes did not control the same specific behavior (i.e., across participants there was variability in the number and colour of Lego pieces used within classes), from another perspective they controlled the same general behavior of selecting Lego pieces. What is not clear from Experiment 1, though, are the reasons for the variability in responding across stimuli in a class, and the persistence of responding at any one class member. In other words, the question arises as to why training a specific response to one member of an equivalence class is less likely to produce variability in the resulting functional equivalence class than does simply giving a general instruction to respond.

Questions about sources of control over variability (Epstein, 1991; Shahan \& Chase, 2002) are also pertinent to the findings observed across experiments. Compared to Experiment 1 where not all participants used the Lego pieces, all participants in Experiment 2 now placed Lego pieces into the plastic boxes containing the class stimuli. In addition, there was a more orderly distribution of Lego pieces across class members and persistence in Lego 
selection across trials for each class member. In Experiment 3, there was a further decrease in the variability of responding across participants; for the most part, there was no responding at all at 'A2', 'B2', and 'C2'. Interestingly, the issue of variability raised in these studies may be related to findings in previous studies which examined the effects of prior history (e.g., Moxon et al., 1993; McGlinchey, Keenan, \& Dillenburger, 2000; Watt, Keenan, Barnes, \& Cairns, 1991). Although these studies did not examine functional equivalence classes per se, they demonstrated that variability in equivalence responding was significantly influenced by prior social history.

Regarding the combinations of behaviors that appeared at 'A1', it is unclear at present how this finding is to be viewed. Clearly the finding is of interest to questions about how repertoires compete and interact over time because of effects of multiple control of behavior (Epstein, 1991). However, it is not clear from the data reported here if a combination of behaviors is to be considered as a functionally distinct emergent unit of behavior (i.e., a blend). Perhaps future studies could examine this question by firstly generating a combination of behaviors as shown here (see also Schenk, Keenan \& Morren, 2015) and then training relations with new stimuli (e.g., A1-D1, A1-E1, etc) to see if the combinations remain intact when tested at these other stimuli. Of course, it is entirely possible that contextual control in the equivalence training procedure would result in the dismantling of combined behaviors and for component behaviors to reappear at 'D1' and 'E1'.

The procedures used here differed from procedures normally used to investigate functional equivalence classes in that there were no functions directly trained to stimuli within an equivalence class. Nevertheless, there was clear evidence for the possible emergence of functional equivalence classes. These findings tentatively lend some support to those from Tonneau, Arreola, and Martínez (2006) who concluded that operant reinforcement was not necessary for the occurrence of function-transformation effects. That said, the 
interpretation of the current findings rests on speculation about historical effects of stimuli brought to bear on the design of the testing context. Presumably, discriminative properties of stimuli that comprised the testing context could be derived from a combination of both operant and respondent procedures.

The need to resort to speculation about controlling variables could be viewed as weakness of the current studies. However, similar problems have plagued the analysis of performance of basic schedules of reinforcement were multiple determination of behaviour is recognised (Keenan \& Toal, 1991; Zeiler, 1984). Patterning of responding on a schedule of reinforcement was never seen as problematic even when it was difficult to isolate controlling variables. Whilst no single functional relation has been identified in the current experiments, the overall effects were replicable and therefore constitute a challenge to inductive science, not a reason to dismiss their relevance to the existing body of findings in this area.

To conclude, there was also clear evidence that combinations of behaviors can be produced in equivalence classes. The robustness of these findings could have implications for the design of studies using observational learning to explore the emergence of functional equivalence responding and the emergence of novel behavior. This suggestion echoes a call by Tonneau Arreola, and Martínez (2006) for a detailed evaluation of the role of nonoperant variables in function transformation. A possible contender for an experiment might be to use the stimulus pairing observation procedure (SPOP), a respondent-type training procedure (Leader, Barnes, \& Smeets, 1996) which differs substantially from the matching-to-sample procedure used in this study. In the SPOP procedure, a response is not required from the participant in order for training trials to be delivered. Testing procedures used in the current study could be used with the SPOP procedure to see whether or not results similar to those reported here would be obtained. 


\section{References}

Albright, L., Schnell, L., Reeve, K.F., \& Sidener, T. M. (2016). Using stimulus equivalencebased instruction to teach graduate students in applied behavior analysis to interpret operant functions of behavior. Journal of Behavioral Education, 25, 290-309. https://doi.org/10.1007/s10864-016-9249-0

Barnes, D., Browne, M., Smeets, P., \& Roche, B. (1995). A transfer of functions and a conditional transfer of functions through equivalence relations in three-to six-year-old children. The Psychological Record, 45(3), 405-405. https://doi.org/10.1007/BF03395464

Barnes, D., \& Keenan, M. (1993). A transfer of functions through derived arbitrary and nonarbitrary stimulus relations. Journal of the Experimental Analysis of Behavior, 59(1), 61-81. https://doi.org/10.1901/jeab.1993.59-61

Barnes-Holmes Y., Barnes-Holmes, D., Smeets P. M., Strand, P., \& Friman, P. (2004). Establishing relational responding in accordance with more-than and less than as generalized operant behavior in young children. International Journal of Psychology and Psychological Therapy, 4, 531-558.

Retrieved from https://www.ijpsy.com/volumen4/num3/

Bones, R., Keenan, M., Askin, D., Adams, L., Taylor, D., \& Nicholas, O. (2001). The effects of response topography on functional equivalence class formation. The Psychological Record, 51, 89-110. https://doi.org/10.1007/BF03395388

Dougher, M. J., Augustson, E. M., Markham, M. R., Greenway, D. E., \& Wulfert, E. (1994). The transfer of respondent eliciting and extinction functions through stimulus equivalence classes. Journal of the Experimental Analysis of Behavior, 62, 331-351. http://doi.org/10.1901/jeab.1994.62-331 
Dougher, M. J., Hamilton, D. A., Fink, B. C., \& Harrington, J. (2007). Transformation of the discrimi- native and eliciting functions of generalized relational stimuli. Journal of the Experimental Analysis of Behavior, 88, 179-197. https://doi.org/10.1901/jeab.2007.45-05

Dougher, M. \& Markman, M. R. (1994). Stimulus Equivalence, Functional Equivalence and the Transfer of Function. [Chapter 4. In] Hayes, S. C. Hayes, L. J. Sato, M., \& Ono, K. (1994). Behavior Analysis of Language and Cognition. Reno, NV: Context Press.

Dougher, M., Twohig, M. P., \& Madden, G. J. (2014). Editorial: Basic and translational research on stimulus- stimulus relations. Journal of the Experimental Analysis of Behavior, 101, 1-9. https://doi.org/10.1002/jeab.69

Dymond, S., \& Rehfeldt, R. A. (2000). Understanding complex behavior: The transformation of stimulus functions. The Behavior Analyst, 23, 239-254. https://doi.org/10.1007/BF03392013

Dymond, S., Roche, B., Forsyth, J. P., Whelan, R., \& Rhoden, J. (2007). Transformation of avoidance response functions in accordance with the relational frames of same and opposite. Journal of the Experimental Analysis of Behavior, 88, 249-262. https://doi.org/10.1901/jeab. 2007.22-07

Epstein, R. (1991). Skinner, creativity, and the problem of spontaneous behavior. Psychological Science, 2, pp. 362-370. https://doi.org/10.1111/j.14679280.1991.tb00168.x

Fields, L., \& Watanabe-Rose, M. (2008). Nodal structure and the partitioning of equivalence classes. Journal of the Experimental Analysis of Behavior, 89, 359-381. https://doi.org/10.1901/jeab.2008-89-359 
Fields, L., Landon-Jimenez, D. V., Buffington, D. M., \& Adams, B. J. (1995). Maintained nodal-distance effects in equivalence classes. Journal of the Experimental Analysis of Behavior, 64(2), 129-145. https://doi.org/10.1901/jeab.1995.64-129

Gatch, M. B., \& Osborne, J. G. (1989). Transfer of contextual stimulus function via equivalence class development. Journal of the Experimental Analysis of Behavior, 51, 369-378. https://doi.org/10.1901/jeab.1989.51-369

Hayes, S. C., Barnes-Holmes, D., \& Roche, B. (Eds.) (2001). Relational frame theory: A post-Skinnerian account of human language and cognition. New York: Plenum.

Hayes, S. C., \& Hayes, L. J. (1989). The Verbal Action of the Listener as a Basis for Rule Governance. In S. C Hayes (Ed), Rule-Governed Behavior: Cognition, Contingencies and Instructional Control (pp.153-190). New York, NY: Plenum Press.

Keenan, M., Porter, I., \& Gallagher, S. (2015). Merging separately established functional equivalence classes. The Psychological Record, 65(3), 435-450. https://doi.org/10.1007/s40732-015-0118-3

Keenan, M., Schenk, J., Coyle, C., Reid, L., \& Gallagher, S. (2020). The Effects of Social Labels on the Allocation of Resources to Equivalent Stimuli: Does One Rotten Apple Spoil the Whole Barrel? The Psychological Record, https://doi.org/10.1007/s40732$\underline{020-00423-0}$

Keenan, M., \& Toal, L. (1991). Periodic reinforcement and second-order schedules. The Psychological Record, 41, 87-115.

Leader, G., Barnes, D., \& Smeets, P. (1996). Establishing equivalence relations using a respondent-type training procedure. The Psychological Record, 46, 685-706. https://doi.org/10.1007/BF03395192 
Ma, M. L., Miguel, C. F., \& Jennings, A. M. (2016). Training intraverbal naming to establish equivalence class performances. Journal of the Experimental Analysis of Behavior, 105, 409-426. https://doi.org/10.1002/ jeab.203

McGlinchey, A., Keenan, M., \& Dillenburger, K. (2000). Outline for the development of a screening procedure for children who have been sexually abused. Research on Social Work Practice, 10, 722-747. https://doi.org/10.1177/104973150001000604

McGuigan, S., \& Keenan, M. (2002). Rule following in functional equivalence classes. European Journal of Behavior Analysis, 1, 21-29. https://doi.org/10.1080/15021149.2002.11434201

McVeigh, B., \& Keenan, M. (2009). Multiple Functions in Equivalence Classes. Psychological Record, 59, 93-118. https://doi.org/10.1007/BF03395651

Moxon, P. D., Keenan, M., \& Hine, L. (1993). Gender-role stereotyping and stimulus equivalence. The Psychological Record, 43, 381-394. Retrieved from https://link.springer.com/journal/40732/43/4

Nichols, A. L., \& Maner, J. K. (2008). The Good-Subject Effect: Investigating Participant Demand Characteristics. The Journal of General Psychology, 135(2), 151-165. http:// doi.org/10.3200/GENP.135.2.151-166.

Perez, W. F., Fidalgo, A. P., Kovac, R., \& Nico, Y. C. (2015). The transfer of Cfunc contextual control through equivalence relations. Journal of the Experimental Analysis of Behavior, 103, 511-523. http://doi.org/10.1002/jeab.150

Pilgrim, C. (2016). Considering definitions of stimulus equivalence. European Journal of Behavior Analysis, 17:1, 105-114, DOI: 10.1080/15021149.2016.1156312

Pilgrim, C. (2019). Equivalence-based instruction. In J. O. Cooper, T. E. Heron, \& W. L. Heward. Applied Behavior Analysis (3rd Edition) (pp. 496-539). Hoboken, NJ: Pearson Education. 
Shahan, T. A., \& Chase, P. N. (2002). Novelty, stimulus control, and operant variability. The Behavior Analyst, 25, 175-190. https://doi.org/10.1007/BF03392056

Schenk, J. J., Keenan, M., \& Morren, J. (2015). Using multiple functions within equivalence classes to generate novel responding. European Journal of Behavior Analysis, 16:1, 99-111. http://dx.doi.org/10.1080/15021149.2015.1066156

Sidman, M. (1994). Equivalence Relations and Behavior: A research story. Boston, MA: Authors Cooperative.

Sidman, M., \& Tailby, W. (1982). Conditional discrimination vs. matching to sample: An expansion of the testing paradigm. Journal of the Experimental Analysis of Behavior, 37, 23-44. https://doi.org/10.1901/jeab. 1982.37-5

Tonneau, F., Arreola, F., \& Martinez, A. G. (2006). Function transformation without reinforcement. Journal of the Experimental Analysis of Behavior, 85, 393-405. http:// doi.org/10.1901/jeab.2006.49-05

Valverde, M. R., Luciano, C., \& Barnes-Holmes, D. (2009). Transfer of aversive respondent elicitation in accordance with equivalence relations. Journal of the Experimental Analysis of Behavior, 92, 85-111. http://doi.org/10.1901/ jeab.2009.92-85

Walker, B.D. \& Rehfeldt, R.A. (2012). An evaluation of the stimulus equivalence paradigm to teach single-subject design to distance education students via blackboard. Journal of Applied Behavior Analysis, 45, 329-344. https://doi.org/10.1901/jaba.2012.45-329

Watt, A., Keenan, M., Barnes, D., \& Cairns, E. (1991). Social categorization and stimulus equivalence. The Psychological Record, 41, 33-50. https://doi.org/10.1007/BF03395092

Whelan, R., \& Barnes-Holmes, D. (2004). The transformation of consequential functions in accordance with the relational frames of same and opposite. Journal of the 
Experimental Analysis of Behavior, 82, 177-195.

https://doi.org/10.1901/jeab.2004.82-177

Zeiler, M. D. (1984). The sleeping giant. Journal of the Experimental Analysis of Behavior, 42, 485-493. 


\section{Figure Captions}

Fig. 1. Results obtained from participants who progressed to the Phase 4 (testing for emergent relations) in Experiments 1 and 2. Data are grouped according to three patterns of responding that were observed. Group 1, P4 and P6 are shown at the top; Group 2, P8 and P9 are shown in the middle; Group 3, P2 and P7 are shown at the bottom. Left-hand panels show results for Experiment 1 and Right-hand panels show results for Experiment 2. Alphabetical order is used when more than one Lego piece was selected.

Key: 'B' = Blue Lego, 'G' = Green Lego, 'R' = Red Lego, 'Y' = Yellow Lego, '-' = Lego joined, ' $\mathrm{X}$ ' = No response.

Fig.2. The results obtained across trials for all participants during Phase 4 (testing for emergent relations) in Experiment 3. Alphabetical order is used when more than one Lego piece was selected.

Key: 'B' = Blue Lego, 'G' = Green Lego, 'R' = Red Lego, 'Y' = Yellow Lego, 'X' = No response. 
Fig. 1.

\begin{tabular}{|c|c|c|c|c|c|c|c|c|c|c|c|c|c|}
\hline & \multicolumn{6}{|c|}{$\begin{array}{c}\text { P4 } \\
\text { Experiment 1 }\end{array}$} & \multicolumn{6}{|c|}{$\begin{array}{c}\text { P4 } \\
\text { Experiment } 2\end{array}$} & \\
\hline Trial & $\begin{array}{l}\text { A1 } \\
\text { ZID }\end{array}$ & $\begin{array}{l}\text { B1 } \\
\text { KAP }\end{array}$ & $\begin{array}{l}\mathrm{Cl} \\
\mathrm{TV}\end{array}$ & $\begin{array}{l}\mathrm{A2} \\
\mathrm{YIM}\end{array}$ & $\begin{array}{l}82 \\
\text { DOJ }\end{array}$ & $\begin{array}{l}\text { C2 } \\
\text { VEK }\end{array}$ & $\begin{array}{l}\text { A1 } \\
\text { ZID }\end{array}$ & B1 & C1 & $\begin{array}{l}\text { A2 } \\
\text { YIM }\end{array}$ & $\begin{array}{l}\text { B2 } \\
\text { DOJ }\end{array}$ & $\begin{array}{l}C 2 \\
\text { VEK }\end{array}$ & Trial \\
\hline 1 & $x$ & $x$ & $x$ & $x$ & $x$ & $x$ & 8 & G & 8 & $x$ & $\mathrm{x}$ & $x$ & 1 \\
\hline 2 & $x$ & $x$ & $x$ & $x$ & $x$ & $x$ & 8 & $G$ & B & $x$ & $x$ & $x$ & 2 \\
\hline 3 & $x$ & $x$ & $x$ & $\mathrm{X}$ & $x$ & $x$ & G & B & B & $x$ & $\mathrm{X}$ & $x$ & 3 \\
\hline 4 & $x$ & $x$ & $x$ & $x$ & $x$ & $x$ & B & G & B & $x$ & $x$ & $x$ & 4 \\
\hline \multirow[t]{2}{*}{5} & $x$ & $\mathrm{X}$ & $x$ & $x$ & $x$ & $x$ & B & G & B & $x$ & $x$ & $\mathrm{x}$ & 5 \\
\hline & \multicolumn{6}{|c|}{$\begin{array}{c}\text { PG } \\
\text { Experiment 1 }\end{array}$} & \multicolumn{6}{|c|}{$\begin{array}{c}\text { P6 } \\
\text { Experiment } 2\end{array}$} & \\
\hline Trial & $\begin{array}{l}\text { A1 } \\
\text { ZID }\end{array}$ & $\begin{array}{l}\text { B1 } \\
\text { KAP }\end{array}$ & $\begin{array}{l}\mathrm{C} 1 \\
\mathrm{TIV}\end{array}$ & $\begin{array}{l}\mathrm{A} 2 \\
\mathrm{YIM}\end{array}$ & $\begin{array}{l}82 \\
\text { DOJ }\end{array}$ & $\begin{array}{c}\text { C2 } \\
\text { VEK }\end{array}$ & $\begin{array}{l}\text { A1 } \\
\text { ZID }\end{array}$ & B1 & $\mathrm{Cl}$ & $\begin{array}{l}\text { A2 } \\
\text { YIM }\end{array}$ & $\begin{array}{l}82 \\
\text { DOJ }\end{array}$ & $\begin{array}{l}\text { C2 } \\
\text { VEK }\end{array}$ & Trial \\
\hline 1 & $x$ & $x$ & $x$ & $x$ & $x$ & $x$ & BG & 8 & G & $x$ & $x$ & $x$ & 1 \\
\hline 2 & $x$ & $x$ & $x$ & $x$ & $x$ & $x$ & BG & B & G & $x$ & $x$ & $x$ & 2 \\
\hline 3 & $x$ & $x$ & $x$ & $x$ & $x$ & $x$ & BG & B & G & $x$ & $x$ & $x$ & 3 \\
\hline 4 & $x$ & $x$ & $x$ & $\mathrm{x}$ & $x$ & $x$ & BG & 8 & G & $x$ & $x$ & $x$ & 4 \\
\hline 5 & $x$ & $x$ & $x$ & $\mathrm{X}$ & $x$ & $x$ & 86 & 8 & G & $x$ & $x$ & $x$ & 5 \\
\hline
\end{tabular}

\begin{tabular}{|c|c|c|c|c|c|c|c|c|c|c|c|c|c|}
\hline & \multicolumn{6}{|c|}{$\begin{array}{c}\text { P8 } \\
\text { Experiment 1 }\end{array}$} & \multicolumn{6}{|c|}{$\begin{array}{c}\text { P8 } \\
\text { Experiment 2 }\end{array}$} & \multirow[b]{2}{*}{ Trial } \\
\hline Trial & $\begin{array}{l}\text { A1 } \\
\text { ZID }\end{array}$ & $\begin{array}{l}\text { B1 } \\
\text { KAP }\end{array}$ & $\begin{array}{l}\mathrm{Cl} \\
\mathrm{TIV}\end{array}$ & $\begin{array}{l}\text { A2 } \\
\text { YIM }\end{array}$ & $\begin{array}{l}B 2 \\
\text { DO }\end{array}$ & $\begin{array}{l}C 2 \\
\text { VEK }\end{array}$ & $\begin{array}{l}\text { A1 } \\
\text { ZID }\end{array}$ & B1 & $\mathrm{Cl}$ & $\begin{array}{l}\text { A2 } \\
\text { YIM }\end{array}$ & $\begin{array}{l}\text { B2 } \\
\text { DOJ }\end{array}$ & $\begin{array}{l}C 2 \\
\text { VEK }\end{array}$ & \\
\hline 1 & $Y$ & $\gamma$ & $Y$ & $R$ & $R$ & $R$ & G-B & 8 & G & $\mathbf{R}$ & $R$ & $R$ & 1 \\
\hline 2 & $Y$ & $Y$ & $Y$ & $R$ & $R$ & $R$ & G.B & 8 & G & R & $R$ & $R$ & 2 \\
\hline 3 & $Y$ & $\gamma$ & $Y$ & $R$ & $R$ & $R$ & G.B & $B$ & G & $\mathbf{R}$ & $R$ & $R$ & 3 \\
\hline 4 & $Y$ & $\gamma$ & $\gamma$ & $R$ & $R$ & $R$ & G-B & B & G & R & R & $\mathbf{R}$ & 4 \\
\hline \multirow[t]{2}{*}{5} & $Y$ & $\gamma$ & $\gamma$ & R & R & $R$ & G-B & 8 & G & $R$ & R & R & 5 \\
\hline & \multicolumn{6}{|c|}{$\begin{array}{c}\text { P9 } \\
\text { Experiment 1 }\end{array}$} & \multicolumn{6}{|c|}{$\begin{array}{c}P 9 \\
\text { Experiment } 2\end{array}$} & \\
\hline Trial & $\begin{array}{l}\text { A1 } \\
\text { ZID }\end{array}$ & $\begin{array}{l}\text { B1 } \\
\text { KAP }\end{array}$ & $\begin{array}{l}\mathrm{C} 1 \\
\mathrm{TNV}\end{array}$ & $\begin{array}{l}\text { A2 } \\
\text { YIM }\end{array}$ & $\begin{array}{l}B 2 \\
\text { DO }\end{array}$ & $\begin{array}{l}\text { C2 } \\
\text { VEK }\end{array}$ & $\begin{array}{l}\text { A1 } \\
\text { Z1D }\end{array}$ & B1 & $\mathrm{C} 1$ & $\begin{array}{l}\text { A2 } \\
\text { YIM }\end{array}$ & $\begin{array}{l}82 \\
\text { DOJ }\end{array}$ & $\begin{array}{l}C Z \\
\text { VEK }\end{array}$ & Trial \\
\hline 1 & BR & R & G & RY & G & BR & $8 G$ & G & B & RY & B & $R$ & 1 \\
\hline 2 & $B R$ & G & G & RY & RY & $R$ & $B G$ & G & B & RY & BY & $R$ & 2 \\
\hline 3 & $B R$ & GY & RY & GY & B & GR & BG & G & B & RY & BY & GY & 3 \\
\hline 4 & BG & RY & RY & GY & BR & GR & BG & G & $B$ & RY & BY & GY & 4 \\
\hline 5 & BG & AY & RY & BG & BR & GR & $G B$ & G & 8 & RY & $\mathrm{BY}$ & $G Y$ & 5 \\
\hline
\end{tabular}

\begin{tabular}{|c|c|c|c|c|c|c|c|c|c|c|c|c|c|}
\hline & \multicolumn{6}{|c|}{$\begin{array}{c}\text { P2 } \\
\text { Experiment 1 }\end{array}$} & \multicolumn{6}{|c|}{$\begin{array}{c}\text { P2 } \\
\text { Experiment 2 }\end{array}$} & \\
\hline Trial & $\begin{array}{l}\text { A1 } \\
\text { ZID }\end{array}$ & $\begin{array}{l}\text { B1 } \\
\text { KAP }\end{array}$ & $\begin{array}{l}\mathrm{Cl} \\
\mathrm{TNV}\end{array}$ & $\begin{array}{l}\text { A2 } \\
\text { YIM }\end{array}$ & $\begin{array}{l}B 2 \\
\text { DOJ }\end{array}$ & $\begin{array}{l}\text { C2 } \\
\text { VEK }\end{array}$ & $\begin{array}{l}\text { A1 } \\
\text { ZID }\end{array}$ & B1 & $\mathrm{Cl}$ & $\begin{array}{l}\text { A2 } \\
\text { YIM }\end{array}$ & $\begin{array}{l}B 2 \\
\text { DOJ }\end{array}$ & $\begin{array}{l}C 2 \\
\text { VEK }\end{array}$ & Trial \\
\hline 1 & GG & BRY & BBB & $\mathrm{rrr}$ & $x$ & $\begin{array}{l}\text { GGGG } \\
\text { GGCS }\end{array}$ & BB & GG & RY & $r$ & $x$ & GG & 1 \\
\hline 2 & BBB & RR & GGG & $\mathrm{mY}$ & RY & $\begin{array}{l}\text { OGGG } \\
\text { GGG }\end{array}$ & 88 & BB & RY & RY & BB & GR & 2 \\
\hline 3 & $B B R$ & $x$ & BG & RY & $B R$ & GGG & BBR & RR & GR & RY & BRY & BG & 3 \\
\hline 4 & BR & $\gamma$ & BR & BY & $x$ & GGGG & BBRR & GG & BB & BRY & BBR & $x$ & 4 \\
\hline \multirow[t]{2}{*}{5} & RRRR & $\gamma$ & BQGR & $\mathrm{BrYY}$ & $x$ & GGGG & 88 & BR & BB & RY & RY & G & 5 \\
\hline & \multicolumn{6}{|c|}{$\begin{array}{c}\text { P7 } \\
\text { Experiment } 1\end{array}$} & \multicolumn{6}{|c|}{$\begin{array}{c}\text { P7 } \\
\text { Experiment } 2\end{array}$} & \\
\hline Trial & $\begin{array}{l}\text { A1 } \\
\text { ZID }\end{array}$ & $\begin{array}{l}\text { B1 } \\
\text { KAP }\end{array}$ & $\begin{array}{l}\mathrm{C} 1 \\
\mathrm{TN}\end{array}$ & $\begin{array}{l}\text { A2 } \\
\text { YIM }\end{array}$ & $\begin{array}{l}B 2 \\
\text { DOJ }\end{array}$ & VEK & A1 & B1 & $\mathrm{C} 1$ & $\begin{array}{l}\text { A2 } \\
\text { YIM }\end{array}$ & $\begin{array}{l}82 \\
\text { DOJ }\end{array}$ & $\begin{array}{l}C 2 \\
\text { VEK }\end{array}$ & Trial \\
\hline 1 & B.-B.y & $r-B-B$ & B.r. & h-G.k & GRR & A-12.6 & $\mathbf{A - B}-\mathbf{G}$ & B-y-y & G.X-Y & A-YY-R & r-p-R & A-A- $-\boldsymbol{\gamma}$ & 1 \\
\hline 2 & B.B.YY & Y-B.B & B.Y.8 & R.G.R & $G \cdot R \cdot R$ & R.R.G & $8-8-6$ & B.Y & G.X & R.Y.R.R & $r-x, A-n$ & $n-n \cdot y-n$ & 2 \\
\hline 3 & B-B-y & Y-B-B & 8-r.8 & R-G-k & G.k-n & H-N.G & $\begin{array}{l}B-G-B . \\
G-6\end{array}$ & $B$ & 6.6 & $Y-k-x-q$ & Y-R & $\begin{array}{l}Y-R-\gamma- \\
R-Y-R\end{array}$ & 3 \\
\hline 4 & 8.8.6 & 6.8.8 & 8.68 & A.Y.K & $Y R \cdot R$ & R.A.Y & B-G-Y & B.Y & GY & Y.RY,R & $Y-R \cdot R$ & $Y-R=R$ & 4 \\
\hline 5 & B-8-y & $Y=B-B$ & B-Y.B & $R \in R$ & $G \cdot R \cdot R$ & R-R.G & B.G.Y & B.Y & G.Y & $Y-R=Y-R$ & Y-R.R & YRR R & 5 \\
\hline
\end{tabular}


Fig. 2.

\begin{tabular}{|c|c|c|c|c|c|c|}
\hline & $\begin{array}{l}\text { A1 } \\
\text { ZID }\end{array}$ & B1 & C1 & $\begin{array}{l}\text { A2 } \\
\text { YIM }\end{array}$ & $\begin{array}{l}\text { B2 } \\
\text { DOJ }\end{array}$ & $\begin{array}{l}\text { C2 } \\
\text { VEK }\end{array}$ \\
\hline Trial & \multicolumn{6}{|c|}{ P10 } \\
\hline 1 & BBBBBBBGGGGGGGG & $\mathrm{x}$ & $x$ & $\mathrm{x}$ & $x$ & $x$ \\
\hline 2 & BBBBBGGGGG & GGGGG & BBBBB & $\mathrm{x}$ & $\mathrm{x}$ & $x$ \\
\hline 3 & BBBBBGGGGG & BBBBB & GGGGG & $x$ & $\mathrm{x}$ & $x$ \\
\hline 4 & BG & G & B & $\mathrm{x}$ & $\mathrm{x}$ & $\mathrm{x}$ \\
\hline \multirow[t]{2}{*}{5} & BG & G & $\mathrm{B}$ & $\mathrm{x}$ & $\mathrm{x}$ & $\mathrm{x}$ \\
\hline & \multicolumn{6}{|c|}{ P11 } \\
\hline 1 & BG & G & $B$ & $\mathrm{Y}$ & $\mathrm{R}$ & GY \\
\hline 2 & BG & G & B & $Y$ & $R$ & GY \\
\hline 3 & BG & G & B & $Y$ & $\mathrm{R}$ & GY \\
\hline 4 & BG & G & B & $\mathrm{R}$ & $Y$ & GY \\
\hline \multirow[t]{2}{*}{5} & BG & G & $\mathrm{B}$ & $Y$ & $\mathrm{R}$ & GY \\
\hline & \multicolumn{6}{|c|}{ P12 } \\
\hline 1 & BG & G & B & $x$ & $x$ & $\mathrm{x}$ \\
\hline 2 & BG & G & B & $\mathrm{x}$ & $\mathrm{x}$ & $\mathrm{x}$ \\
\hline 3 & BG & G & $B$ & $\mathrm{x}$ & $\mathrm{x}$ & $\mathrm{x}$ \\
\hline 4 & BG & G & B & $\mathrm{x}$ & $\mathrm{x}$ & $\mathrm{x}$ \\
\hline \multirow[t]{2}{*}{5} & BG & G & $\mathrm{B}$ & $\mathrm{x}$ & $\mathrm{x}$ & $\mathrm{x}$ \\
\hline & \multicolumn{6}{|c|}{ P14 } \\
\hline 1 & BGGGRRYYY & GGGGG & BBBBB & $\mathrm{x}$ & $\mathrm{x}$ & $\mathrm{x}$ \\
\hline 2 & BBBBRYYY & GGGG & BBBB & $\mathrm{x}$ & $\mathrm{x}$ & $\mathrm{x}$ \\
\hline 3 & BBBBBGGGRY & GGGG & BBBB & $\mathrm{x}$ & $\mathrm{x}$ & $\mathrm{x}$ \\
\hline 4 & BBBBBGGGGG & GGGGG & BBBBB & $x$ & $\mathrm{x}$ & $x$ \\
\hline 5 & BBBBBGGGGG & GGGG & BBBB & $x$ & $\mathrm{x}$ & $x$ \\
\hline
\end{tabular}

